\title{
Learning to Be Practical: A Guided \\ Learning Approach to Transform \\ Student Community Resilience When \\ Faced with Natural Hazard Threats
}

\author{
Justin Sharpe (1)
}

\begin{abstract}
This chapter seeks to explore how creative use of educational resources can challenge students to take responsibility for their own preparedness and safety in response to natural hazard risks. A brief context for the need for learning-focused rather than education-focused curriculum is explored before the England and Wales context is brought into focus. Two methods for transforming learning around the theme of natural hazard risk and response are offered: A film project in which students produce films by and for children and youth and a 'Go-Bag' project in which students take on a practical task of making up a real emergency bag. By guiding student learning, but allowing it to develop inside a reasonable framework, student learning was not only deeper on a cognitive level, but also allowed students to understand their own roles and responsibilities in responding to natural hazard threats. The combination of both is explored through the use of an online questionnaire $(n=176)$ in which the impact of the learning on students and their families are explored. The classroom and individual learning activities' impact on student efficacy are discussed alongside the results from the questionnaire. Findings included support for prior assumptions about the impact of school-based learning on the family with regard to disaster preparedness as well as deeper cognition regarding the risks and increased self-efficacy in students. The implications for these findings and their role in transforming learning to enhance community resilience that starts with the family are discussed with the door to future research nudged open.
\end{abstract}

\section{Introduction}

J. Sharpe $(\bowtie)$

Department of Geography, King's College London, London, UK

e-mail: justin.sharpe@kcl.ac.uk
Education for disaster risk reduction and resilience was a central tenet of the Hygo Framework for Action which ran from 2005 to 2015 (HFA 2005), 
and during which time, the classroom activities outlined in this chapter took place. The HFA was itself, partially drawn up in response to the number of losses and damages wreaked by disasters on human populations and the environment. A key tenet of the HFA involved the use of: 'knowledge, innovation and education to build a culture of safety'. It is argued here that this was based on an assumption that if individuals have the 'appropriate' knowledge and education, a culture of safety will follow. However in practice, information alone is insufficient to lead to action (e.g. Kolmuss and Agyeman 2002, Demos/Green Alliance 2003, Talbot et al. 2007) leading to a Value Action Gap (Blake 1999).

Consequently, there is a strong argument that learning is an essential starting point for allowing resilient individuals and communities to develop. The term 'learning' is purposefully used here. The definition of learning taken, is one in which the outcome leads to: 'a change in knowledge, beliefs, behaviours or attitudes that is the result of experience' (e.g. Ambrose 2010). Moreover, learning is also understood to be both experiential and socially constructed with the power to become transformative when learners are challenged and given the expertise, knowledge and time for reflection (Sharpe 2016).

Further research by Sharpe and Kelman (2011), notes that in relatively affluent places such as England, doubt about the effectiveness of particular measures, lack of belief in one's personal ability to carry them out and apathy in considering a situation deemed to be unlikely to occur, provide a number of obstacles to successful education and learning regarding DRR, something supported by other researchers (e.g. Lindell and Perry 2000; Mulilis and Duval 1995; Ronan et al. 2001).

Overcoming such barriers can be helped by drawing on a body of pedagogical research that indicates that experiential learning has the potential for motivating people to action (Dewey 1938; Kolb 1984). Much of the impetus for experiential learning has come as a reaction to overly didactic, teacher-controlled learning. Assumptions about learning from experience are that experience provides the foundation of, and the stimulus for learning; that learning is a socially and culturally constructed process influenced by the socio-emotional context in which it occurs; and that learners actively construct their own learning experience (Boud et al. 1993). Those assumptions have been challenged through critical analysis of experiential learning theory (e.g. Fenwick 2001) but the theory has then been extended and reworked to try to overcome those challenges, such as for management learning (Kayes 2002).

Consequently, activities that allow for the experiential and explorative learning, might be more meaningful at transforming the views, attitudes and behaviours of students. Furthermore, other researchers examining the impact of hazards education on children in formal education have assumed that there is some form of transmission to family and the wider community (Gordon et al. 1999; Peek 2008). However, this has not been widely tested or reported while, moreover, parents might not be engaged in the learning in the same way as their child. This has the potential to undermine school learning and is why it has been argued that it is important that students of school age have access to: "information that helps a child understand what he or she can do relatively independently to be prepared physically and emotionally" (Ronan and Johnston 2003, p. 1011). As a result, the curriculum by the author of this chapter was developed with the intension of addressing these issues, while making the learning fun, engaging and useful for students, who are shrewd observers and assessors of what is relevant to them.

This chapter therefore outlines how the curriculum was developed and employed to improve communication of hazards in general, including those of a volcanic nature to both children and by extension their family and the wider community. It does this by detailing how the curriculum was designed and delivered in a manner that allowed for guided learning that permitted students to explore key issues of risk, response and preparedness for themselves and their family. Furthermore, it provides evidence of how students developed self-efficacy (belief in their ability to carry out a task) through a curriculum that married 
guided learning with practical tasks. It is argued that this engaged students in disaster learning, while enabling them to become agents of change in their community, starting with their family as suggested by other researchers (e.g., Gordon et al. 1999; Peek 2008), but not widely tested. The curriculum development and subsequent research methodologies outlined below have strong roots in prior pedagogies for tackling disaster risk reduction education. These have been expanded upon through the development and use of novel and engaging teaching and learning. This includes practical approaches to embedding critical reflection as a way of strengthening understanding of hazard risks (including volcanic ones) and appropriate responses to them. It is contended that this creative and guided learning, opens up avenues of understanding that can make crisis communication more readily accepted and acted upon by the wider community, building outwards from school based education to engage students and their families.

\section{Disasters and Geography-The UK Context}

The study of school Geography in the United Kingdom is governed by the National Curriculum, which sets out what must be studied, but not the format or style of delivery. At key stage three (11-14 years of age) students are regularly assessed on their progress via a means of testing, essay writing, or project based homework in order to ascertain a National Curriculum Level mark. However, although this tests knowledge, understanding and retention of facts/figures, it does not allow for all learning styles to be accommodated, nor does it test for learning or a change in attitude or behaviour, which is often the goal of disaster risk reduction and resilience educators. (e.g. HFA 2015).

Disasters themselves can be included in curriculum, but often take a top-down approach of response or governmental planning approach to the mitigation of tectonic hazards in particular while not allowing for the roles and responsibilities of the individual to come to the fore (e.g.
Sharpe and Kelman 2011). The following section outlines how a curriculum was planned and executed in response to this gap.

\section{The School Context}

The activities outlined here, were developed for students in early high school (aged 11-14; known in the UK as key stage 3) for inclusion in mainstream natural hazards focused geography lessons. The teaching activities, learning outcomes and survey were all carried out at Beal High school, Ilford, Essex, while the author was working as a teacher of geography.

The school's ethnic mix at the time was approximately $65 \%$ Southern Asian origin (Indian, Pakistani and Bengali), with the children often the first generation born in the UK; $25 \%$ White (including those from across Europe) and $8 \%$ Afro-Caribbean and approximately $2 \%$ of Chinese origin. Many of the children of South Asian origin visited areas of the world where tectonic and hydro-meteorological hazards were both more frequent and of a higher magnitude and yet were unaware that these dangers might present themselves when visiting grandparents and other family in their parents' country of origin. This was a primary concern when setting out the curriculum.

The lessons were planned in order to fit within the National Curriculum while encouraging exploration through provided mediums such as web sites, video and mapping exercises, experimentation through the creation of student films and learning by doing, which allowed for real emergency 'Go-Bags' to be produced as part of a homework task. The students followed a unit of the geography curriculum (approximately eight to nine weeks) called 'Dangerous Geography' in which the geography of hazards, response and preparedness were to be explored. ${ }^{1}$ This was

\footnotetext{
${ }^{1}$ A complete description of the Unit 1 'Hazards and How to Prepare for Them' module, lesson plans and resources can be found on the authors website, created to help teachers and educators find creative and effective ways of enaging children of all ages in hazards education. This can be viewed at: http://www.edu4drr.org/page/curriculum-1.
} 
primarily carried out in year seven (11-12 year olds) while future learning in year eight (1213 year olds) addressed the scientific aspects of plate tectonics, earthquakes and volcanoes. This allows for learning to be built slowly rather than attempting to cram everything together in one unit that students become tired of.

\section{The Approach}

Being a classroom practitioner allowed me to take an action research approach while forming and developing curriculum and pedagogies as part of my ongoing professional practice. This afforded a unique perspective, in so much as allowing the author's pedagogical approach to being a reflective practitioner with regards to curriculum development and delivery, to sit alongside that of a researcher whose role is more analytical in observing and evaluating the various nuances of learning and their role in changing cognition and behaviour towards disaster risk.

The research decision to collate data was not made when the curriculum was initially in development, but when the curriculum had been running for two years. This allowed for a period of 'bedding in' of the curriculum with small tweaks made in collaboration with departmental colleagues in order to have a greater impact on knowledge and understanding that might unlock deeper learning. The decision to initiate a questionnaire was taken to inform our teaching practice by capturing the impact of the overall curriculum in terms of preparedness and efficacy of response of children and their families. The study was a pilot study, in that although the curriculum had been taught through several times, there was only one set of data collected $(n=175)$ at the time as the author moved on the following year. The use of data collection via an online survey was agreed with departmental staff as well as senior management in the school. It was agreed that an online format questionnaire would allow students to retain anonymity, permitting them to be honest with their feedback. The questionnaire therefore served a dual role: on the one hand it allowed teaching professionals to evaluate the impact of the curriculum in order to continue to develop, it, while on the other hand it allowed for research into wider issues of impact on family preparedness that have been assumed, but not more widely investigated.

The author was the primary researcher. There were no other researchers in a formal sense, but discoveries, information, lessons learned were shared informally by the other geography teachers (there were three others) within department meetings, but also on a day-to-day basis during break or lunch times. This is an important and neglected area of learning - the contribution of informal feedback with colleagues that allow for curricular to be honed, improved and extended to allow for deeper level learning. This shows the importance of informal socially constructed learning that takes place among reflective practitioners in the teaching of geography.

In particular, this might be viewed as a type of as social learning, of which there are many different descriptions, but the one used here is what McCarthy et al. (2011) summarised as an on-going, adaptive process of knowledge creation that is scaled-up from individuals though social interactions fostered by critical reflection and the synthesis of a variety of knowledge types that result in changes to social structures (e.g. organizational mandates, policies, social norms). In this case, it would mean the tweaking of the curriculum to help students engage with it more readily or to adapt certain parts for students with different competencies of literacy and numeracy or other cognitive needs.

The curricula was created and shared by myself with the other teachers in the department and advice was offered and support given when teachers were challenged by any of the activities. Each teacher followed the curricular as lesson plans and resources were provided and talked about prior to delivery. The questionnaire was deemed to be a reasonable way of allowing the department to ascertain the impact on cognition over a longer time, rather than just after a test or other formalised evaluation. The questions were shared with the other teachers and they were given access to the questionnaire prior to it going 
live and students asked to complete it three weeks following the last lesson in the 'Dangerous Geography' unit of work.

\section{Methods}

There were 246 students that this particular study assessed as part of an evaluation of the effectiveness of curriculum based methods for learning how to acknowledge, respond to and prepare for a range of hazards, including those of a volcanic nature. During the filming stage all students participated in the storyboarding, filming and editing of films. Students were split into groups of five or six to achieve this task and while some students were more assertive on the filming tasks, others were more so on the planning or editing phases. This allowed for students with stronger skillsets, talents and learning styles (Gardner 1993, 1999) to develop roles that they felt comfortable in while also challenging others to learn new skills and develop communication and team-working skills as part of the learning process.

Approximately 40 videos were produced in total, but only a small number (12) were added to the YouTube channel (www.youtube.com/ edu4hazards) as these were deemed to be accurate in their advice and representation of the correct behaviours and actions.

All students $(246=$ total $)$ were asked to complete a survey three weeks following the end of the unit of work, in order for them to have time for reflection as well as attempting to ascertain how much had been retained (not just mentally but physically in terms of emergency Go-Bags and their role in family life). 175 students out of $246(71 \%)$ completed the online survey, which was completed at home or in the school library if internet access was not available at home. This was chosen for ease of answering the questions, as well as to limit bias by having a teacher nearby or looking over student shoulders when they carried out the survey. The questions were also asked at random, rather than in the same order each time so that if students worked together on laptops when at a friend's house they would find it harder to crib from their friend's answers.

\section{The Lessons}

A complete description of the Unit 1 'Hazards and How to Prepare for Them' module, lesson plans and resources can be found at: http://www. edu4drr.org/page/curriculum-1. However a brief outline is given below in order to provide context for this approach as a method for engaging and developing the minds of adolescents for learning to cope with the dangers of a variety of hazards (Fig. 1).

In lesson one, students identified a number of hazards from a word puzzle while the differences between hazards and disasters were explored, before examining a video about Hurricane Katrina in which students learned what was known before and what occurred afterwards in order to explore the impact of humans in the causation of disasters. Following a mapping exercise of disasters in the USA in lesson two, lesson three introduces the concept of how geography can save lives. Students examined the example of Tilly Smith, an English school girl who was the same age as them when she recognised the signs of a tsunami in Thailand and warned her parents who alerted hotel staff and evacuated the beach in 2004, saving many lives. Subsequently, time was given over to what an emergency Go-Bag might be, what it might contain and what could and should be included in their own one. This lesson and subsequent individual 'thinking and doing' tasks are laid out as a separate case study in this chapter.

The lessons following this allowed for student creativity and exploration to become part of the learning process as students storyboard, planned, filmed, edited and presented their films to the class. This took place over three one-hour lessons and the principal guidance was that students must take information from the edu4hazards.org website, created by Sharpe (2007), (see Fig. 2) which was researched and cross-checked with sources such as the International Federation of Red Cross websites and publication (IFRC 2013) 


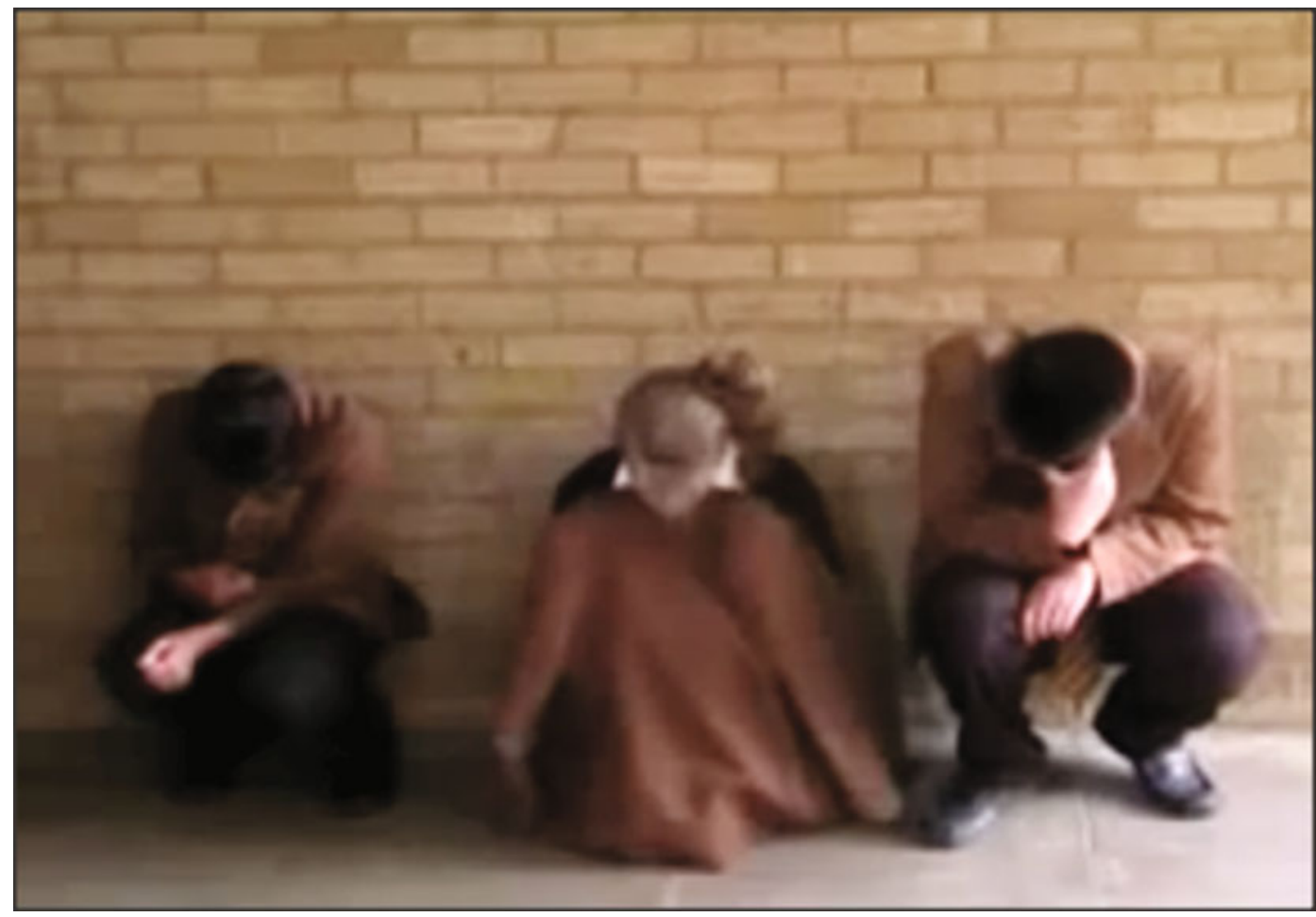

Fig. 1 Film still from student film about what to do in case of a volcanic eruption

and other factually reliable websites in order for the most current information regarding appropriate responses to a range of hazards to be included.

The learning material supporting the edu4hazards website allows for a variety of learning strategies to be utilised to allow students to engage with the material in different ways (Sharpe and Kelman 2011). Furthermore the production of the films was to ascertain the level of knowledge and understanding about the hazards, risk and response, with students informed that films with misleading or inaccurate information could not be shared on the YouTube channel. It was explained that films would be evaluated by their peers for accuracy, creativity and usefulness to others.

Following these lessons a further set of six to eight one hour lessons examined flood causes, risk and response, and preparation, as this was considered to be most relevant to a local context, with the nearby River Roding having flooded in the past with relative frequency (10-20 years). At the end of the entire dangerous geography unit the students were tested using an end of unit examination with overall grades moderated and decisions made about grade boundaries and how these might equate to National Curriculum levels.

\section{Case Study 1: The Volcanic Hazard Films}

Students were allowed to work with their friends and decided for themselves what hazards interested them most. Some demonstrated an interest in volcanic hazards as this appealed to them as individuals and volcanoes and their associated hazards are quite an abstract concept for students in the UK.

The first task was the production of a storyboard. This required inter-personal and intrapersonal learning skills as well as a degree of creativity. This stage is also important for a 


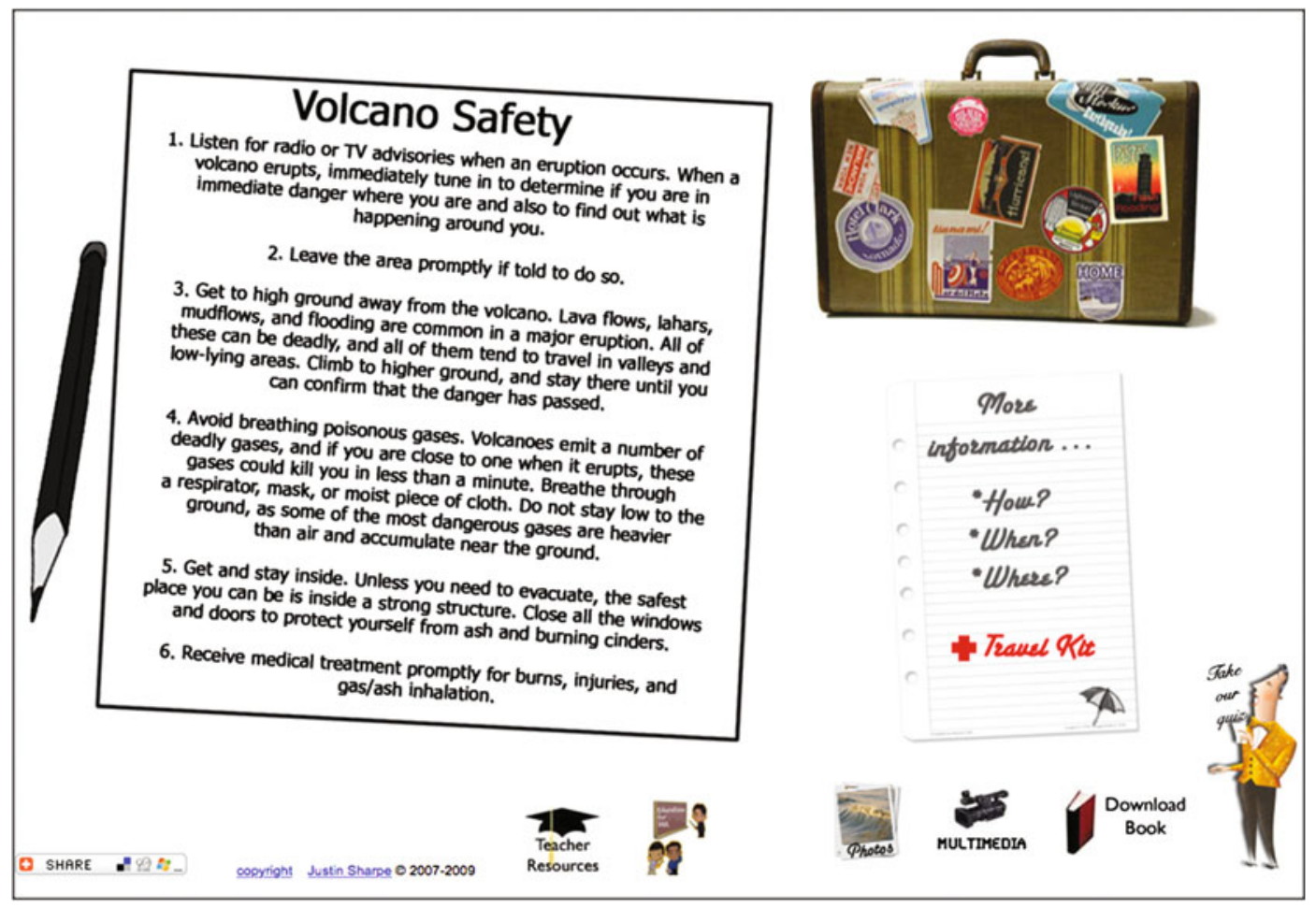

Fig. 2 Screengrab from edu4hazard.org website regarding volcano saftety

teacher to help students negotiate potential pitfalls as well as guiding students to stay focussed on the task at hand. Each location (around the school grounds) was identified by students as well as alternatives if the weather was inclement on the day of filming. Storyboards were viewed by the class teacher and students were allowed to complete outside class if they wished, but a photograph of each group's storyboard was also taken so that if a child was absent with illness for instance, a copy could be printed off for use by the group. Students were then allowed to go and film what they needed, following and using their storyboards which provided structure and allowed for an easier editing process as a result.

Following editing, student films were imported to the class computer and shared with the class. The group that had made the film answered questions about their film, as part of the assessment and evaluation phase of the lesson.

Students films were assessed (by the students, and the teacher) on:
- the basis of content knowledge (e.g., what they remembered about volcanic hazards). This was carried out by comparing the information about the volcanic hazard as an image file on the board as a means of cross referencing that the information given was accurate and well presented.

- the 'correct response' to natural hazards events. This was assessed in terms of how seriously protective action was carried out and whether students had made assertions that were incorrect, misleading or dangerous. Again students and occasionally the teacher highlighted these points as part of the 'two stars and a wish' (see Table 1) process of evaluation. This requires students to make two positive comments about what they had seen and one suggestion to improve it. This allows for reflection and framing of their thoughts in a constructive manner.

- how they communicated the potential dangers. For instance, the actions shown in the 
Table 1 A pre-defined feedback matrix given to students to allow them to critically evaluate the success of disaster safety films produced by their peers

What examples from the film helped you understand how to respond to and prepare for the hazard?
What might the film-makers do to be more successful in communicating appropriate responses to the hazard? film alongside any narration needed to match up well and exhibit creativity and realism.

In the films the students acted out many of the mitigation practices such as:

(a) getting to higher ground away from the volcano;

(b) covering mouths and noses to prevent ash inhalation, and

(c) evacuation tips.

These films can be found online. ${ }^{2}$

Following the making, editing and showing of the films, students provided feedback to each other using peer-evaluations from a pre-defined matrix (Table 1). The goals were to:

- critique each others as well as their own films;

- identify mistakes and to take away lessons learned.

Students were encouraged to write their own responses first, before agreeing and providing feedback in the 'two stars and a wish' format.

Students thought about how such films might be used in a real crisis by scientists and disaster managers to inform the public. This was brought out via questioning in the classroom by teachers and was used as an extension to the main learning in an effort to stretch the critical thinking skills of the more able students and is evidence of planning for students with various levels of academic ability.

\footnotetext{
${ }^{2}$ YouTube (See: French version: https://www.youtube. com/watch?v=2jSLqlE0TWw; English version: https:// www.youtube.com/watch?v=xljmjuVwJy8\&list=UUarOr dsyYX7rTWV-9cKH3mw).
}

\section{Why Film-Making Was Deemed Important for Understanding Responding to Risk}

Using video for pedagogical purposes, Goodyear and Steeples (1998), suggest that the use of video can provide a platform through which to articulate tacit information and knowledge that may be difficult to describe through text, while Hempe (1999), refers to the strength of video as a visual demonstration, dramatization or presentation of visual evidence, while making an emotional appeal to the viewer. Both were demonstrated through watching student-made films. This outcome was not discussed or shared with the students at the time, due to time constraints of the curriculum, but could certainly be developed further for cross-curricular days in schools, when more time is allowed for critical thinking and reflection.

A further reason for developing films that advised how to survive tectonic or hydro-meterological hazards was in response to the way that students used YouTube and Tumblr on their tablets and mobile phones for both fun, interaction with their peers and as sources of information. Conversations with students in class (by the researcher and classroom teacher) revealed that they saw these sites as trustworthy sources of information, much like previous generations may have gleaned information from documentaries on TV and prior to that, in the cinema. Furthermore, Wahlberg and Sjoberg (2000); Weingart and Pansegrau (2003), note that in post-industrial society the media have become highly influential and powerful in the communication of complex scientific, technological and political changes. However, media organisations 
may also have political and financial motives for distorting or 'spinning' the scientific, technological or political changes or discoveries: e.g. climate change denial.

Consequently, films by children and youth, for children and youth allow students to take control of the process for themselves, with no other motive other than helping others. This is a yet unexplored realm of research within disasters and yet has been explored in other fields. However, Sharpe (2016) points to the work of Taylor (2002) who cites studies that go beyond an ego-centred motivations, such as: inclusive of spirituality, a transpersonal realm of development (Cochrane 1981; Hunter 1980; Scott 1991; Sveinunggaard 1993; Van Nostrand 1992), compassion for others (Courtenay et al. 1998; First and Way 1995; Gehrels 1984), and a new connectedness with others (Gehrels 1984; Laswell 1994; Weisberger 1995).

Furthermore, the role of the teacher in the transmission of curricula, can be a positive influence in development of critical thinking. A good teacher should allow for the provision of interesting counterpoints to certain arguments, while the inclusion of opposing views are given space with students given the time to explore, debate and decide for themselves. Having said this, the role of the curricula can be used to address any factual misconceptions (about natural hazards, the risk they pose and appropriate responses) in order to contribute to students 'schema' of understanding (existing frameworks of ideas and concepts; e.g., Rumelhart and Norman 1978) of hazards and human response to disaster. If students have realistic expectations about the nature of natural hazards and the steps that can be taken towards preparing for them, it is more likely that they will do so in the future when they are adults, while also developing their sense of self-efficacy as adolescents.

These issues will be explored further in the discussion section, which follows the second case study in which emergency go-bags were created and the impact of the overall curricula and practical implications and learning was tested using an online survey.

\section{Case Study Two: 'Go-Bags' and Post Curricula Survey}

During the 'Go-Bag' lessons students were encouraged to talk about what might be useful to include in an emergency 'Go-Bag'. This took the form of a 'Think, Pair, Share' exercise in which time was given over to individual thinking before student ideas are shared with a neighbour and then with the class. The contents of two emergency go-bags held in the geography department were examined before students voted on which was better and why. This allowed for the development of critical thinking as well as reflection and re-purposing of thoughts in the light of new learning. A homework task was set out introducing the edu4hazards.org website and focusing on the emergency kit or 'Go-Bag' page. Students were informed that these items are 'ideal' for a Go-Bag, but they might think of others too.

A further caveat was introduced in order to be as inclusive as possible: students and their families were encouraged to keep costs low and not spend more than $£ 5.00-£ 8.00$ on their kits or 'Go-Bags'. Suggestions were shared with students about the likely places to find such items, including online sources. A week or two was allowed for the completion of homework tasks as it was understood that if resources were sourced on the internet using free delivery it might take longer. It is therefore important that practical considerations are thought out before setting such tasks and discussing these with colleagues prior to the lessons taking place allows for a consistent expectations across the year group.

Lesson time was given over to students bringing in and talking through what they had in their kits, with students asking questions and making suggestions for improvement. Again the method used was 'two stars and a wish' (see Table 1) so that the process is not about overtly criticising, but learning from and developing ideas further. In this way, students self-evaluate with guided learning facilitated by the teacher. This allows for a more equal student-teacher and student-student interaction facilitated by reducing any power relationships and hierarchy, in order to promote more of an exchange, with each 
party supporting and gaining from the other. Again critical thinking is fundamental, with learning process facilitated by the teacher, similar to the 'guided discovery' approach used in international development and advocated by Bruner (1961).

The questionnaire approach was used to ascertain the level of understanding students had developed as well as understanding how they did or did not engage with the material, the practical tasks and the impact on extending learning into the family home. While there was a small element of group activity and development of critical thinking in class, the 'Go-Bag' homework exercise was designed to allow students to explore how they might prepare themselves and the extent to which family members became involved in the process.

\section{Data Collection and Analysis}

\subsection{Case Study One: Volcanic Hazard Films}

Several types of data was collected in this part of the study, including observations of student learning and an analysis of their knowledge and understanding tested through the making of the volcanic hazard films. The following section describes what was carried out, including an analysis of the significance of the film-making process as a way of framing new learning. As students were responsible for their own films, they had to synthesise what they had learned, thinking though the most appropriate ways to communicate risk both visually and via the narrative. The significance of this and its effect on deeper learning, including the wider impact on community hazard resilience is also encompassed in the interpretation and discussion section that later in the chapter.

Observations/Teacher account of making and editing phases included the authors observations coupled with discussions with the other classroom teachers in the department. Again this was part formal and part informal especially during the chaos of teaching and learning how to edit videos, which was a new skill for some teachers in the department. Being an observant and reflective practitioner was an effective methodology for analysing pedagogical approaches and learning outcomes. These reflections are also associated with transformational learning practices (Mezirow 1995) that might allow for teachers to make sense of what they are doing in order to learn from, test, reflect, test and learn as a continuation of their professional development.

Classroom observations during the 'premieres' of student-made videos was a purposefully discrete process that allowed students to explore their roles as responsible media, whose role was to inform and engage learners of a similar age by critiquing their own and others films. These self and peer evaluations and discussions of videos were useful for (re)-framing what messages were important, the role played by media in education and learning, as well as the need for accurate, independent and trusted content.

Consequently, discussions about each film became an important part of the evaluative process, as students realised and acknowledged their mistakes in a nurturing environment, in which learning from mistakes became integral to deeper learning outcomes. Discussions of negative implications included:

- 'What would happen if videos were put on YouTube with the wrong or exaggerated information?';

- 'What did you learn or understand about how you can protect yourself in the event of a volcanic hazard?';

- 'What shouldn't you do when treating a burn?'

The videos were evaluated by students using a 'Geography-Factor' (an 'X-Factor' format that provided a framework for them to think differently, allowing them to hold different perspectives and viewpoints as they analysed the videos), in order to hold their attention and to take on various roles for feeding back. This also challenged students to acknowledge their own 'automatic thoughts' (Mezirow 1995) and reactions when 
seeing something for the first time and allowed for more considered and reflected upon responses. Furthermore they learned to be analytical while also understanding the position of others.

Researcher analysis of videos was carried out in an open manner and shared with students as a way to summarise how an 'expert' might critique the videos and the legitimate reasons for doing so.

Formal assessment of the module was carried out in an end of unit examination and given an England and Wales National Curriculum Level mark. Scores were based on students overall knowledge and understanding, A higher weight being given to understanding borne out by an ability to explain, reason and argue the merits of enacting responsible behaviours and actions regarding hazard preparation, including those for volcanic hazards.

These written tests (including differentiated versions for students of a lower ability) were also used to assess overall knowledge and understanding four weeks after completing this initial part of the unit of work. ${ }^{3}$

\subsection{Case Study Two: 'Go-Bags' and Post-curricula Survey}

Three weeks after the completion of the scheme of work, which included the unit on flooding following the overall hazards lessons and activities, an online post-hazard survey was produced $^{4}$ and students asked to complete. These were completed by 175 students. The aim of the survey was to evaluate their level of engagement with the curriculum, the impact of practical tasks, such as making their own 'Go-Bag' and the extent to which the use of a practical task that required parental input, helped or impacted on discussions of safety and practical preparedness in the home. The most

\footnotetext{
${ }^{3}$ See: http://www.edu4drr.org/page/curriculum-1; Unit 1; Lesson 7).

${ }^{4}$ See: http://www.esurveyspro.com/SummaryReport.aspx? SurveyId $=37283 \&$ sel $=0$.
}

salient findings from a research perspective are included below:

- 114 students $(65 \%)$ reported talking to parents about what they had been learning about. This is significant as it shows a high level of engagement, but this was also not an accident, as the homework task actively encouraged students to talk to parents when putting a kit together.

- Consequently, 130 (74.3\%) reported putting emergency kits('Go-Bags') together with their parents. Of these, $65(37.1 \%)$ were helped by mothers, 19 (10.9\%) by fathers, with $37(21.1 \%)$ helped by both and the remaining $13(7.4 \%)$ helped by a sibling in the family home.

- A further 109 students (65\%) discussed what they had been learning in class which included hazards and preparedness generally.

- In terms of the utility of the 'Go-Bags' exercise, only 20 students (10.9\%) claimed that they no longer had the bag or it was thrown away, which meant that just over $88 \%$ still had their kits and with $47 \%$ reporting that the kit was in a place easily accessible to all (e.g. by the front door, in a cupboard under the stairs etc.).

In terms of the curricula leading to better levels of preparedness, students were asked: Do you think that your household is better prepared for emergencies as a result of what you have learned about and shared with you family? In response to this, 96 students $(54.9 \%)$ reported that there household was better prepared, with 27 $(15.4 \%)$ saying no and $47(26.9 \%)$ not sure. This was in fact very helpful. Because a large proportion of students were not sure, teachers asked why this was the case. Reasons that were fed back, included: being more prepared in some ways but not in others such as not having equipment in a 'Go-Bag' for the whole family; parents not taking the exercise seriously or believing that there might be an occasion to use the kit. This led to conversations about how a go-bag might be useful for holidays in places where there were risks of earthquakes, flooding 
and volcanic eruptions. This neatly rounded the learning off, as this was also one of the first conversations about hazards and risk that had taken place at the beginning of the unit.

This engagement with the practical task of making an emergency kit/go-bag led to further discussion about what students were learning. This included (according to parents and students at parent-teacher conferences) talking about the video tasks and the reasons for actively preparing for disasters even in a country where disasters are often seen as part of the 'other' because they happen to other people, despite large scale flood events and even events such as heatwaves in 2003, which killed 2091 in England alone (Johnson et al. 2005).

Some students commented that their parents carried emergency kits for the car. A few noted that their parents already had a kit in their car and this led to classroom discussions surrounding the reasons for this (with reasons including that it came with the car or they had decided that it was a prudent precaution when children were born) which also allowed for students to understand how their parents looked after them in previously unseen or unheard ways.

\subsection{Post-lesson Parent-Teacher Conferences}

There is evidence that the curriculum reached beyond the classroom, as parents from different classes (around twenty across the year group) engaged in animated discussions with all of the teachers from the geography department at parent-teacher conferences about the 'Go Bags' homework exercise. Some reported as liking it for engaging 'their son/daughter in doing something practical', while others reported enjoying being involved with their son/daughter's school work. Some parents reported that they also engaged with the practical aspect of preparing kits as well as learning about what happens elsewhere.

Furthermore, some parents also talked about their own experiences of hazards, trauma, and preparedness in their country of origin, but these were not noted down at the time, for ethical reasons.

\section{Interpretation/Discussion}

Interpretation and discussion of the two case studies are carried out below in order to frame their relative importance to overall impact of the learning on both students and their families.

\subsection{Case Study 1: Volcanic Hazard Films}

Students responded well to the idea of making videos/films that were made by people their own age, for people their own age. Providing trusted sources of information was discussed as well as why these were trusted sources of information, such as use of the latest scientific information to aid student understanding. This allowed students to assimilate information for themselves as well as thinking how they might synthesise it for others. Different learning styles, in particular intrapersonal, interpersonal, artistic, linguistic and kinaesthetic (learning through movement or the physicality of undertaking a task) were accessed and utilised in order to help students learn while also providing them the opportunity to teach others. Playing roles or writing the dialogue required students to think about what they might do in the event of a volcanic crisis. ${ }^{5}$ Again, this allows critical thinking and reflection skills to be developed as well as being able to show empathy for others by thinking about the implications of disasters on families in different parts of the world.

Furthermore, by understanding the effects of volcanic eruptions, it also allowed students to ask questions of why and how. These questions are provided as a sub-menu on the www. edu4hazards.org website ${ }^{6}$ as well as the answers

\footnotetext{
${ }^{5}$ Student written, directed and edited video in French can be viewed at: https://www.youtube.com/watch?v= 2jSLqlE0TWw\&list=PL8785FE43DBE2F748\&index $=4$.

${ }^{6}$ This website was created by the author in 2007 as a way of engaging children and youth in learning what simple practical measures could be effectively carried out to prepare for natural hazards. It's development and subsequent early use as an educational tool can be found in the UNISDR publication: Towards a Culture of Prevention: Disaster Risk Reduction Begins at School: Good Practices and Lessons Learnt' UNISDR (2007).
} 
which are provided on web pages when students interact with the menu. This sets up a chain of self-discovery that is not directed by a teacher or educator telling students to look or explore; they do this for themselves! Students would ask questions based on what they had seen and this allowed the author to talk about this with them or to direct them to explore further, suggesting other websites they could look at too.

By involving students on their own terms, allowing them to explore their own interests (through the media and specific hazard-topic) they took charge of the learning and produced their own educational materials. This allowed for a high level of participation, both in the classroom and independently, as students were empowered to make their own choices about what to film, how to film it and the information that it should contain.

- Through active planning and participation, students gained a deeper understanding of why actions (such as preparing 'Go-Bags' specific to volcanic crises) are effective at reducing risk while taking steps to ensure their own safety following a natural hazards event.

- Students shared the 'difficulties' of planning, filming and editing, thus allowing for socially constructed learning to take place and enabling transformative learning through a process of critical reflection. Teachers observed that some groups worked well together immediately, while other's struggled to get the balance right, needing more time to negotiate personality conflicts for instance. This type of group dynamic is important to acknowledge and learn from.

- The film-making making, editing and critiquing allowed students to engage in an evaluative and reflective process. This allowed them to be rigorous with the evaluation of their own and others films, while learning about how to respond to volcanic eruptions, as they thought about and acted out how to successfully demonstrate the correct behaviours.
Central to this pedagogical approach was the empowerment of students as knowledge bearers to others and their reflection on their own learning process (i.e., metacognition; Sterling 2011).

\subsection{Case Study Two: Go Bags and Post-lesson Survey}

Of the surveys completed, a high proportion (75\%) reported that they had collated their emergency kits with their parents. This actively involved parents in asking the reasons for such an exercise, with several parents (six or seven across the department) calling the department to ask for clarification or wanting to know more.

A large proportion of returned surveys (almost $55 \%$ ) reported that they did feel more prepared as a family following the lessons, with their corresponding activities and individual projects (the films) and home learning (the 'Go-Bags'). This was an important finding as it supported earlier suggestions by Gordon et al. (1999) and Peek (2008), that students can be agents of change within the family with regard to responding to the hazard risk.

However, there were still almost $27 \%$ that were unsure, which initially suggested that perhaps not enough had been done to engage students. However, on further inquiry (asking the students), it was found that the barrier was the result of some parents dismissing the exercise as "not useful", because they didn't believe that a hazard event would precipitate the use of 'go-bags' and evacuations. Students facing such obstacles in their own families might be challenged by these views. However, this should not be seen as a barrier but an opportunity to engage in debate and learning across the family. However, if they can make up their own mind and carry out their own protective behaviours, these thoughts and actions may allow them to gain personal efficacy and slowly transform their own learning in order to be better prepared personally. 


\subsection{Case Study Two: Parent-Teacher Meetings}

Conversations with parents at parent-teacher meetings allowed for further reflection as well as parents to show their interest or ask questions about the learning. The bullet points below summarise the key points from these meetings:

- Sharing lesson(s) with parents and siblings allowed for a wider form of transformative learning to be initiated within the local community as well as within the school and classroom.

- Students acted as important agents of change by discussing the film project and 'Go Bags' with their parents and other relatives.

- This 'bottom-up' approach to learning about volcanic hazards led to a wider discussion about hazards in their families.

\section{Conclusions}

The filming and 'Go-Bags' lessons incorporated practical skills which used authentic, practical tasks and peer evaluation that could play a role in transformative learning. In particular, having the spaces for relational learning and reflection may allow students to negotiate potential cognitive conflicts that occur when their new knowledge and understanding may be threatened by the views of others who are important influences in their life, such as the views of parents, the content of religious teachings or other socio-cultural influences. Mezirow (2000) refers to this process as Reflective Dialogue in which a consensus is negotiated with others regarding prior learning, assumptions and actions. However, Mezirow's transformative learning theory has focused on the development of the adult mind to coping with change brought about through experience of training, but it may well mean that this may occur earlier than previously thought and this study tends to support this premise.
Experiential learning, reflection and the act of playing out the threats from hazards provides a space to move beyond knowledge and towards action. By planning, scripting and then acting out and filming in films about volcanic hazards, students placed themselves in the role of reacting to the threat appropriately, while being in a safe, unthreatening environment. As mentioned earlier this allowed students to draw on a range of learning styles and skills while learning new ones, including developing empathy for others, critical thinking skills, intrapersonal skills (following instructions and thinking about and acting on them in the most appropriate way) as well as opportunity for creativity and more.

In terms of volcanic crises communication, the research presented here illustrated that children can and do act as agents of change for their families, supporting prior research that highlighted the importance of engaging children in learning about disasters (e,g., Gordon et al. 1999; Peek 2008). In particular, students reported a higher belief in the efficacy of the family to face future hazard events as the result of their learning, task completion and practical exercises. However, the use of the questionnaire also allowed for further reflection and for a probing of the reasons for uncertainty that still existed in some cases. This could then be discussed further and resolved to a certain extent. This is significant because it shows that deeper reflection could occur with guidance from the teacher as a way of working through problems and unexpected outcomes together.

Furthermore, reflection and evaluation (peerand self-) are key building blocks to improving self-efficacy and new ways of thinking which Mezirow (2012), describes as allowing individuals to "...negotiate and act on our own purposes, values, feelings, and meanings rather than those we have uncritically assimilated from others - to gain greater control over our lives as socially responsible, clear thinking decision-makers" (2012, p. 76).

Finally, aside from these media, others such as puppetry, performance, and music are also 
excellent ways of getting across messages about risk, response and preparedness. ${ }^{7}$ To this end, the author has also developed a comic strip to tackle hazard safety and preparedness for very young children which includes volcano safety alongside, earthquake, tsunami, lightning, flood, evacuations and family planning for such events. This has been used as a pilot project in Iran (Sharpe and Izadkhah 2014) before being produced as a book for children in Pakistan by UNESCO. ${ }^{8}$ In particular, the research described by Sharpe and Izadkhah (2014) show that even at a young age, complex cognitive process were engaged in order for learners to take their new knowledge, place it within the context of their own experience and re-tell it to others.

This pattern of reflection, reasoning and testing is important for deeper learning, which may hold the key to truly resilient individuals and communities. The work outlined here supports this assertion while providing ideas and resources that might usefully be applied to engaging communities in thinking about their own risks and in response, developing their own efficacies in planning and preparing for them.

It is hoped that education and learning that use creative and engaging lessons, materials and resources will continue to challenge and engage children and youth in learning how to prepare for and respond to natural hazard threats and that this has the ability to translate into home safety when students engage their parents in discussion and more importantly, action through practical exercises such as the creation of emergency 'Go-Bags' for the home.

\section{References}

Ambrose SA, Bridges MW, DiPietro M, Lovett MC, Norman MK (2010) How learning works: seven research-based principles for smart teaching. JosseyBass: San Francisco

\footnotetext{
${ }^{7}$ The resources and information to use these activities can be found on the edu4drr website (www.edu4drr.org).

${ }^{8}$ See: http://unesco.org.pk/education/documents/2014/publications/Learning_about_disasters.pdf.
}

Blake J (1999) Overcoming the 'value-action gap' in environmental policy: tensions between national policy and local experience Local Environ 4(3)

Boud D, Cohen R, Walker D (1993) Understanding learning from experience. In: Boud D, Cohen R, Walker D (eds) Using experience for learning. SRHE \& Open University Press, Buckingham, pp 1-17

Bruner J (1961) The act of discovery. Harvard Educational Review 31(1):21-32

Courtenay B, Merriam SB, Reeves PM (1998) The centrality of meaning-making in transformational learning: How HIV-positive adults make sense of their lives. Adult Educ Q 48:65-84

Demos/Green Alliance (2003) Carrots, sticks and sermons: influencing public behaviour for environmental goals. A Demos/Green Alliance report produced for Defra: http://www.demos.co.uk/files/CarrotsSticksSermons.pdf

Dewey J (1938) Experience and education. Macmillan, New York

Fenwick TJ (2001) Experiential learning: a theoretical critique from five perspectives. Information Series No. 385

First JA, Way WL (1995) Parent education outcomes: onsights into transformative learning. Fam Relat 44:104-109

Foley G (ed) (1995) Understanding adult education and training, 2nd edn. Allen \& Unwin, Sydney, pp 225-239

Gardner H (1993) Multiple intelligences: the theory in practice. Basic Books, New York, NY

Gardner H (1999) Intelligence reframed: multiple intelligences for the 21st Century. Basic Books, New York

Gehrels C (1984) The school principal as adult learner. Unpublished doctoral dissertation, University of Toronto, Toronto

Goodyear P, Steeples C (1998) Creating shareable representations of practice. Adv Learn Technol J (ALT-J) 6(3):16-23

Gordon NS, Farberow NL, Maida CA (1999) Children and disasters. Burnner/Mazel, Philadelphia

Hunter EK (1980) Perspective transformation in health practices: a study in adult learning and fundamental life change. Unpublished doctoral dissertation, University of California, Los Angeles, CA

International Federation of Red Cross and Red Crescent Societies (2013) Public awareness and public education for disaster risk reduction: key messages. Accessed online at http://www.ifrc.org/PageFiles/ 103320/Key-messages-for-Public-awareness-guideEN.pdf. Accessed May 2016

Johnson H, Kovaats RS, McGregor GR et al (2005) The impact of the 2003 heatwave on mortality and hospital admissions in England. Health Statistics Q 25:6-11

Kayes DC (2002) Experiential learning and its critics: preserving the role of experience in management learning and education. Acad of Manage Learn Educ 1 (2):137-149

Kolb DA (1984) Experiential learning: experience as the source of learning and development. Prentice Hall, Englewood Cliffs 
Kolmuss A, Agyeman J (2002) Mind the gap: why do people act environmentally and what are the barriers to pro-environmental behavior? Environ Educ Res 8 (3):239-260. doi:10.1080/13504620220145401

Laswell TD (1994) Adult learning in the aftermath of job loss: exploring the transformative potential. In: Hymans M, Armstrong J, Anderson E (eds) 35th annual adult education research conference proceedings. University of Tennessee, Knoxville, pp 229-234 (ERIC Document Reproduction Service No. ED 381 616)

McCarthy DDP, Crandall DD, Whitelaw GS, General Z, Tsuji LJS (2011) A critical systems approach to social learning: building adaptive capacity in social, ecological, epistemological (SEE) systems. Ecol Soc 16(3)

Mezirow J (1995) Transformative theory of adult learning. In: Welton M (ed) In defense of the lifeworld. State University of New York Press, Albany

Mezirow J (2000) Learning to think like an adult: core concepts of transformative theory. In: Mezirow $\mathrm{J}$ et al (eds) Learning as transformation. Jossey-Bass, San Francisco, pp 3-34

Mezirow J (2012) Learning to think like an adult: core concepts of transformation theory. In: Taylor EW, Cranton P (eds) The handbook of transformative learning. Jossey-Bass, San Francisco, pp 73-95

Mitchell JT (2009) Hazards education and academic standards in the Southeast United States. Int Res Geogr Environ Educ 18(2):134-148

Moss R (1983) Video, the educational challenge. Croom Helm Ltd, London and Canberra

Peek L (2008) Children and disasters. Child Youth Environ 18. Retrieved Aug 2011, from http://www. colorado.edu/journals/cye/181/index.htm

Ronan KR, Johnston DM (2003) Hazards education for youth: a quasi-experimental investigation. Risk Anal 23:1009-1020

Rumelhart D, Norman D (1978) Accretion, tuning and restructuring: three modes of learning. In: Cotton JW,
Klatzky R (eds) Semantic factors in cognition. Erlbaum, Hillsdale

Scott SM (1991) Personal transformation through participation in social action: a case study of the leaders in the Lincoln Alliance. Unpublished doctoral dissertation, University of Nebraska, Lincoln, Nebraska

Sharpe J (2007) Education for hazards website. www. edu4hazards.org Accessed May 2015

Sharpe J (2016) Understanding and unlocking transformative learning as a method for enabling behaviour change for adaptation and resilience to disaster threats. Int J Disaster Risk Reduction 17:213-219

Sharpe J, Izadkhah YO (2014) Use of comic strips in teaching earthquakes to kindergarten children. Disaster Prevent Manage 23(2):138-156

Sharpe J, Kelman I (2011) Improving the disaster-related component of secondary school geography education in England. Int Res Geogr Environ Educ 20(4): $327-343$

Sterling S (2011) Transformative learning and sustainability: sketching the conceptual ground. Learn Teach High Educ 5(11):17-33

Sveinunggaard K (1993) Transformative learning in adulthood: a socio-contextual perspective, In Flannery D (ed) 35th annual adult education research conference proceedings, Penn State University, University Park, PA, pp 275-280

Van Nostrand JA (1992) The process of perspective transformation: Instrumental development and testing in smokers and ex-smokers. Unpublished doctoral dissertation, Texas Women's University, Denton

Wahlberg AAF, Sjoberg L (2000) Risk perception and the media. J Risk Res 3(1):31-50

Weingart P, Pansegrau P (2003) Perception and representation of science in literature and fiction film. Public Understand Sci 12:227-228

Weisberger RD (1995) Adult male learners in a community college setting: possibilities of transformation. Ed. D. dissertation, University of Massachusetts 
Open Access This chapter is licensed under the terms of the Creative Commons Attribution 4.0 International License (http://creativecommons.org/licenses/by/4.0/), which permits use, sharing, adaptation, distribution and reproduction in any medium or format, as long as you give appropriate credit to the original author(s) and the source, provide a link to the Creative Commons license and indicate if changes were made.
The images or other third party material in this chapter are included in the chapter's Creative Commons license, unless indicated otherwise in a credit line to the material. If material is not included in the chapter's Creative Commons license and your intended use is not permitted by statutory regulation or exceeds the permitted use, you will need to obtain permission directly from the copyright holder. 